\title{
EXPLORING COMPLEXITY OF FIRST NAMES FROM A THEORETICAL APPROACH ${ }^{1}$
}

\author{
SELENE JIMÉNEZ SEGURA \\ Universidad Nacional Autónoma de México, Facultad de Estudios Superiores Acatlán \\ Universidad de Navarra, Campus Pamplona, España ${ }^{2}$ \\ JIMÉNEZ SEGURA, Selene: Exploring complexity of first names from a theoretical \\ approach. Jazykovedný časopis (Journal of Linguistics), 2021, Vol. 72, No 1, pp. 167 - 182.
}

\begin{abstract}
This work explores the possibility of first names as a complex phenomenon in which not only language, but society and culture are involved. Given names are a category of the natural languages in which different facets of human beings as sociocultural subjects are intertwined. Not only do such names belong to the language they are expressed in but also, they integrate their bearers into the social and cultural structure of their communities. By understanding speakers as ongoing members of different groups within the community and by integrating their interaction as well as the symbolic constructions that emerge from such interaction, the category can be conceived as the result of a dynamic relation between a set of inseparable heterogeneous elements. Hence, language in use, society and culture cannot be isolated or considered separately as they all become the category. Because of this, both the process of name-giving (which first names come to be used by) and the changing repertory resulting from such a process becomes of great relevance to this endeavour. Taking these into consideration, a model of a complex adaptive system will be presented to propose the category of first name as its emergent property.
\end{abstract}

Key words: first names, name-giving, complexity, complex adaptive system

"The whole is more than the sum of its parts" Aristotle

There are different aspects to first names, not only do they pertain to the language they are expressed in but also to the culture, society and historical period in which they are given and used. First names establish societal relations among members of a community while separating them from those who are not part of such a group. They carry cultural meanings, and serve to construct both individual and collective identities (Maíz Arévalo, 2010; Aldrin, 2011). Moreover, they change alongside historical events throughout the diachronic extent of human social interaction.

\footnotetext{
${ }^{1}$ I would like to thank Dr Lisa Thurlow for the revision of the English language of this paper.

${ }^{2}$ The proposal presented in this paper is part of an ongoing PhD dissertation at the Universidad de Navarra, Pamplona, Spain.
} 
Thus, given names are not only a grammatical category of language, but one in which usage interlaces with societal and cultural dimensions. In this way of understanding, first names are not only given to individuals but to subjects that become part of the community (societal, cultural and linguistic). Furthermore, they are chosen and attributed by human agents, who belong to such community as well. Therefore, the category results in an active and multifaceted one that can only be fully understood by taking all of its different aspects into consideration.

In this article, given names are thought of as emerging from a complex adaptive system, and not as a preconceived category of language as an abstract entity. They are considered as the result of the dynamic interaction between the different dimensions involved in name-giving processes and practices: linguistic, societal and cultural, both synchronically and diachronically. In such a complex system, speakers interact with one another as ongoing members of diverse human groups, which implies the creation, recreation and transmission of shared symbolic knowledge and norms through the time.

Based on the aforementioned, the aim of this work is to explore the possibility of name-giving processes and practices as a complex adaptive system, and the category of first names as its emergent property taking research from the onomastic sciences $^{3}$ as theoretical guidelines. Furthermore, a model of said system will be proposed and explained as part of this paper. Consequently, the latter will be of an argumentative nature, reflecting on the idea of given names not only as an object study of linguistics but as appropriate to different scientific disciplines such as social and cultural anthropology, sociology, and history.

The theoretical framework underpinning this proposal follows a more interdisciplinary approach integrating concepts and research conducted in social and cultural anthropology, philosophy, mathematics, and linguistics. Nevertheless, for the most part it is conformed by works done in socio-onomastics and its anthroponomastics branch. In that respect, it regards the study of given names in relation to their social and cultural context but not as a cause-effect one as much as a complex phenomenon.

According to Alfredo Díaz Mata (2012), complexity can be understood depending on the discipline and authors being followed. On one hand, it can be related to the general theory of systems (Bertalanffy, 1976), and the later proposal about complex adaptive systems from Santa Fe Institute in the 1980s. Since this position was created from the so-called "hard sciences" (for example Gell-Mann, 1988), it tends to be considered more of a mathematical and quantitative nature. Nevertheless, it does not exclude the possibility of qualitative applications outside a merely quantitative treatment of data.

${ }^{3}$ Onomastic sciences are to be understood in this work as all of those disciplines that address the study of proper names from any perspective, not only from linguistics. 
On the other hand, the concept of complexity can be associated to the social sciences and the philosophy of science in works from scholars like Edgar Morin and Rolando García. This approach is usually considered more of a qualitative type, also relating the idea of complexity with that of interdisciplinarity and transdisciplinarity. From this perspective, a complex phenomenon such as a country economic flow can be studied by breaking the self-imposed limits of scientific disciplines while creating communicative bridges amongst them, and by separating their epistemological basis from that of the positivist mindset.

Due to the fact that the category of given names is regarded here as a "sideproduct" to the continuance and non-lineal interaction between elements pertaining to diverse dimensions, this work incorporates the concept of complexity from these two main foundations. Even though they seem to be contrary, there are actually various meeting points between both proposals. The most important one is the basic idea of what a complex adaptive system is, and all that implies dealing with the resulting phenomena.

The complex adaptive system proposal as well as theories on both general systems and chaos have been applied to research belonging to different social sciences such as anthropology (Mosko - Damon, 2005), archaeology (López Aguilar, 2017), and linguistics (Kretzschmar Jr., 2015). However, it seems that there is no precedent so far on the application of either these to the study on proper names in general and given names in specific. For that reason, it appears to be a novel field to onomastic exploration.

Notwithstanding the above, there is evidence in the onomastic sciences that points to the close relation between first names ${ }^{4}$, society and culture. In this regard there is a considerable number of research done that connect these from either a linguistic, sociological, anthropological, or historical perspective. All of which have, in some way or another, given greater weight to the facet of given names that seems to correspond to the discipline in which they are situated.

It is quite interesting, that many of these studies do in fact undertake an interdisciplinary position to their inquiries. As such, they have actually begun breaking the self-imposed boundaries of different social disciplines and humanities (showing that they are moving towards trans-disciplinarity ${ }^{5}$ ), and have started evidencing the

\footnotetext{
${ }^{4}$ Because the topic of this paper is given names, we will be focusing on them in spite of talking about proper names in more general terms at times.

${ }^{5}$ According to Julieta Haidar (2006), who specialises in cultural semiotics, there are different epistemological stages for scientific development within the disciplines: disciplinarity, multidisciplinarity, inter-disciplinarity and trans-disciplinarity. Inter-disciplinarity is characterised as the construction of common research methods and conceptual frameworks from different disciplines for the study of one same object. That shared object of study is built from all the different perspectives being considered as part of the inquiry. Trans-disciplinarity, on the other hand, refers to the next and ultimate level of scientific development. It breaks the boundaries traditionally given to disciplines and becomes
} 
category as a complex one. Although they belong to the most part of a certain field of study, many do incorporate conceptual frameworks and methods from a diverse group of disciplines because the category itself seems to request it. Accordingly, research following this path seems to be inclined to integrate linguistics, history, sociology and/or anthropology.

On the same note, socio-onomastics (a relatively new branch of onomastics ${ }^{6}$ ) seems to be regarded as meeting the need to integrate the social context to the study of proper names (which given names belong to). For that reason, it seems to respond, at some extent, to the increasing interest among specialists about the connection between names, society and culture. However, it should be noted that there is a general tendency to give a more relevant role to language while leaving both the societal and cultural facets on a side note (cf. Aldrin, 2011; Bramwell, 2012; Ainala - Östman, 2017).

Socio-onomastics has been developed as part of either socio-linguistics or pragmatics (Ainala - Östman, 2017), both belonging to the general area of linguistics. Consequently, the analysis of names in society is of utmost importance since it is concerned with studying their usage and how the repertory varies according to independent variables and even different cultures. For that reason, it finds its object of study in proper names as a linguistic phenomenon at speech level and its main goal in describing them as part of languages in use within their social context. In other words, socio-onomastics is mostly concerned with the study of one aspect to given names but always in relation to the others: both their societal and cultural ones? ${ }^{7}$.

In respect of this, Emilia Aldrin's (2011) and Ellen Bramwell's (2012) doctoral dissertations have greatly contributed to the study of given names in society. Both scholars focus their attention on the usage of first names in the $21^{\text {st }}$ century from a synchronic perspective that begins to incorporate more the social aspect and anthropology as the result of this. Aldrin anchors her work on interactional linguistics and follows the work of anthropological linguists such as Mary Bucholtz and Kira Hall (2005). Meanwhile, Bramwell takes a more socio-linguistic and social anthropological approach to the matter.

a sort of cross-disciplinary perspective to one same object of study previously constructed from an interdisciplinarity perspective.

${ }^{6}$ Demetrio Castro Alfín (2014, pp. 17-18) talks about academic work already done with this orientation in the 1920s. Nevertheless, it was during the late 1960s and the 1970s that the truly sociolinguistic orientation of the branch started, especially in Germany, Scandinavia and the Slavic countries. I would like to thank the reviewers of this paper for their contribution on my better understanding of socio-onomastics history.

${ }^{7}$ Contrary to studies done from a more formal linguistic approach (focusing on the different levels of linguistic analysis: semantics, morphology, syntax etcetera) in which the category is being described as part of the language system without taking into consideration the socio-cultural context. 
Aldrin (2011) deals with the analysis of choices that future parents take regarding the first name they will give to their offspring. She then relates the process of name-giving to the ongoing construction of both the bearer and the bestower's individual identity. Data that empirically substantiates her work comes from surveys done by postal mail and interviews conducted as part of monitored discussion groups. Her work contributes theoretically to that of socio-onomastics in many ways but for the purposes of this article, only a few will be considered.

On the one hand, Aldrin's research offers a non-static, non-perfective way to understand name-giving. She considers it as an opened-ended, dynamic process founded on different stages and not "as a single, simple, performative act" (Aldrin, 2011, p. 394) of bestowing the name to the bearer. For that reason, she recognises the importance of speaker interaction in such a process, and in shaping both the bestower's and bearer's individual identity. On the other hand, her work becomes interesting on the basis of its methodology because she applies both qualitative and quantitative research methods.

As for Bramwell (2012), her work can be regarded as taking a more interdisciplinary orientation to the study of given names. She begins to incorporate ethnographic research methods to collect and interpret data. For the most part, she undergoes field work in the community of her interest, following more of a social anthropological route. Furthermore, the conceptual framework to her inquiry takes not only from linguistics and its different branches but from a diverse range of social sciences. Therefore, the objective of her work not only responds to the sociolinguistic requirement to consider names as part of language in society but to explore different onomastic practices embedded in different cultures and social relations.

The connection between onomastics and anthropology is not new, and there is compelling previous work done on the topic. Rita Caprini's research (2001), for example, proposes to integrate both the methodology and the theoretical framework of what she refers to as the "ethnological sciences" to the study of proper names. Her proposal thus aims at incorporating research methods to construct and interpret proper names as data from social anthropology and ethnology encompassed with linguistics. Furthermore, it establishes a strong conceptual basis to understand proper names not only as part of languages but of cultures and societies as well. In addition, her work overcomes the purely synchronic approach to the issue and contemplates the possibility of integrating the diachronic dimension.

Both Caprini's and Bramwell's research come from the shared idea of language as part of culture emerging from human social interaction. In that regard, they follow work from linguists whose theoretical constructs deviate from that of the structuralist and generativist conception of language as a "contextual-less" and abstract system opposite to speech and performance. For linguists such as Dell Hymes, Edward Sapir and Benjamin Whorf, language cannot be understood without its social and cultural framework, and as part of onomastic research following their teachings, given names are not a separate, independent, unrelated part of the whole. 
In this regard, Aldrin's work contributes with her findings about the importance of human interaction as part of the name-giving process that bestowers undergo. Very much in concordance with both Caprini's and Bramwell's research, she takes a more qualitative approach to the understanding of first names in usage. By having contrasted different data sources, she is able to recognize certain factors that are not expressed by solely analysing data collected from records separated from their sociocultural ties. Quantitative research methods applied to her work seem to be more of a complementary nature to the qualitative one.

Although many works consider society and culture as part of their inquiries about given names related to name-giving processes and practices, they do in fact miss the point of fully integrating culture into their proposals. For the most part culture is considered a closed-ended and discrete category of analysis, many times related to that of nationality, one that can be mostly evidenced by action (such as behaviour and social practices) and beliefs (such as attitudes). Culture as a shared and dynamic symbolic construction that gives meaning to social experience and the way the world is understood seems to be left aside.

Interestingly enough, as part of her conference in the XXVI International Congress of Onomastics, held in Debrecen in 2017, Valéria Tóth regarded culture to be of the utmost importance for the construction and identification of proper names typology. Coming from a linguist point of view, her remark showed the increasing interest among the specialists to break away from the traditional idea of names as part of language unrelated to its context (and usage). For that reason, returning language to its role as part of culture as a cognitive-symbolic endeavour of human beings would contribute to a better understanding of given names as a complex phenomenon. Furthermore, it would gain evidence on the dynamism amongst such category and others, as well as with speakers as socio-cultural subjects.

István Hoffmann and Valéria Tóth's work (2015) from a cognitive-pragmatic perspective results in an interesting contribution. Their article moves towards the construction of personal names typology in relation to cultural naming practices and systems. According to the authors, first names would fall into what they call "chosen names" from a pragmatic point of view and "referential names" from a cognitivesemantic approach. Chosen names are part of a four-way classification of personal names and as such they are characterised by belonging to the "relatively closed" stock of names in use. Meanwhile, from a cognitive-semantic perspective, they are characterised by having the basic function of individualising the bearer within the group.

The proposal seems to include the concept of culture from a more cognitivesymbolic perspective. Nevertheless, when it comes to the semantic characterization of first names it falls into the habitual idea of higher referentiality and meaning vacuity that formal semantics strongly suggests. Furthermore, it is developed only by the relation to other categories within the language system itself. As part of the 
pragmatic perspective, it is suggested that given names are always consciously chosen from a closed, static and pre-existing stock, which is determined by culture but that includes only fixed and unchanging items.

This last idea of first names being organised in a repertory linked to culture and society seems to be recurrent in the specialised literature. For the most part, studies within the onomastic sciences in general, and not only from socio-onomastics, are interested in describing the distribution and trends of first names in relation to the time-space coordinates which they are given and used in (for example: García Gallarín - Bravo Llatas, 2019; Fernández Juncal, 2020). Furthermore, culture seems to be considered as a guideline that organises the stock in every group of people through a certain period of time.

Very much related to this, Demetrio Castro Alfín's work (2014) seems to be relevant. He studies given names from a sociological and cultural history point of view by analysing a corpus gathered from baptismal records of Tudela, a Spanish municipality in the province of Navarre. His interest rests on the change of paradigms alongside cultural and social variation through time. Thus, he studies tradition and innovation within the name system intertwined with socio-cultural features such as religion or fashion from a diachronic perspective. For that reason, personal names are taken as a cultural phenomenon.

Research conducted within the social sciences such as sociology, anthropology and even demographics does in fact consider given names as either a social or cultural phenomenon (many times as both) more than an exclusively linguistic one (for example Fine, 1985; Sangoï, 1985; Offroy, 1992; Moreno Almarcégui - Zabalza Seguín, 1999). Although many works based on these disciplines have more recently become aware of the category as a plausible object of study to their inquiries, they have already integrated personal names for some time now. Studies taken from these perspectives give evidence of first names not only as a category belonging to language but to society and culture as well.

As shown from the diverse range of works within the onomastic sciences, there has been and still is a generalized inclination to comprehend given names as a multifaceted entity; one which requires, regardless of the facet being highlighted, the joint treatment of the category as a unit. The difference among the various approaches seems to be the aspect of given names being focused on (this according to the discipline that the research is being placed in). Nevertheless, at this point it must be noted that even though it is only one side which is being emphasised, the remaining ones are still present in some way or another. This seems to be helpful on finding evidence to start building on the idea of given names as a complex phenomenon.

Another important observation to highlight at this moment is the following: All these studies do in fact take given names in use and not as an abstract category belonging solely to the system of language. By having considered names in usage, 
their connection to the corresponding societal and cultural facets becomes evident leading them to the inclusion of naming practices embedded. What is more, it seems like name usage is linked to the process and practices of name-giving in just about any culture and society. Therefore, name-giving and name usage seem to be as closely connected to the category as to the culture and society they are part of.

Even though studies from the onomastic sciences have shed light on the close connection of first names with society and culture, little or even nothing has been done regarding the possibility of taking such relation as part of a complex adaptive system. There are specialized articles that refer to given names as a complex category without actually tackling all the different implications from the general systems theory perspective. It therefore seems relevant to comment on Carmen Fernández Juncal's paper from 2011, in which the author suggests that the onomastic system can be taken as a diasystem.

Fernández Juncal's work belongs for the most part to the socio-onomastic perspective of first names. It mainly relies on sociolinguistic concepts and methods to characterise the system. In her 2011 article, the author takes a variationist approach to suggest that the system of personal names can be understood as a diasystem. Her proposal, thus, seems to follow the necessity to explain given name complexity, and her solution comes by taking a well-known theoretical framework in linguistics. As such, she proposes that given names do in fact show variation according to the diatopic, diachronic, diastratic and diaphasic axis.

The variationist approach to construct given names as a multifaceted unit poses a variety of issues. For once, since it is mostly involved with the relation between language and society, it leaves culture out of the picture. Even more, the way it understands society is quite related to the demographic and sometimes static social categories of race, age, gender etc., with which given names are tied up by causeeffect relations. Such independent variables, as shown in Aldrin's study (2011), do not seem to be of greater consequence for the organization of the system, at least not as much as social interaction. Furthermore, the possibility of belonging to different social groups at once is not possible within this perspective, nor is the negotiation of both the bestower and the bearer's social positioning as part of the process of namegiving (Aldrin, 2011).

The proposal of this article expects to contribute to a better understanding of given names as a multifaceted entity that encompasses language, culture and society. For that reason, it takes the following key points from previous research done within the onomastic sciences as those just reviewed:

1. Given names can be regarded not only as a linguistic phenomenon but as social and cultural phenomena as well.

2. In order to recognise the multifaceted nature of the category, it is of utmost importance to start from usage and not from the idea of a preconceived one from language. 
3. The traditional dichotomy in linguistics between language (the abstract system) and speech (the usage of such a system) is not pertinent to our endeavour.

4. In usage, there is evidence of the ongoing dynamic relation between categories.

5. First names usage is embedded with the name-giving process and the naming practices.

6. Given names hold a close relation with the contextual surroundings where they are given and used.

7. There are cultural guidelines to choose and prefer given names within each social group and historical period.

8. First names are organised in repertories that can be understood as nominal paradigms.

9. Trends on the stock of given names can be related to social and cultural changes both synchronically and diachronically.

10. Human beings on their role as bestowers undergo the first name-giving process.

11. First names are bestowed to someone, a human being.

12. It is consensual that the main function of a given name is to individualise, thus to distinguish its bearer.

Having all these key points in mind contributes to the possibility of recognizing a complex adaptive system, and its emergent property. In such proposal, language usage, societal interaction and culture as symbolic constructs are indispensable and fundamental elements. Additionally, the basic idea of first names merely given to individualise their bearers must be overcome so that bearers and bestowers begin to be regarded as members of a variety of diverse groups. Based on this, they are to be understood as complex human agents themselves and not as simplified, discrete and passive recipients to cultural and linguistic phenomena.

For the purposes of the model being presented in this paper, the concept of complexity will be taken from two main sources: the so-called "hard sciences" such as mathematics and physics, and both the social sciences and the humanities. As previously stated, these two perspectives seem to share the general idea of what a complex adaptive system is, and the implications of dealing with the resulting phenomena.

In general terms, a complex adaptive system is considered to be a large set of heterogeneous components (of different nature) that interact with each other in an organized way. The dynamic relations between such components create the so-called emergent properties, ${ }^{8}$ which occur precisely because of such interaction between the joint constitutive elements of the system. Therefore, the latter is understood as a whole, or as a unity of inseparable components that cannot be isolated nor

\footnotetext{
${ }^{8}$ What is often thought of as a "side-product".
} 
considered independently. Taking each one of them separately would imply that the emergency is lost alongside with that which most characterises the system.

In addition to the aforementioned, the system is also considered to be adaptive because it is open and maintains continuous communication with its environment. The exchange of information with the surroundings causes the system to enter into periods of instability and further adaptation to the changes coming from outside the system itself. Adapting to such changes allows the system to reach a new state of stability that will always be achieved due, precisely to its ability to learn (Gell-Mann, 1988; Ladyman - Lambert - Wiesner, 2013).

A recurrent example in the specialised literature concerning complex adaptive systems is that of thought and human brain. The latter is conformed from a large number of neurons (preparation of proteins, water and other) that communicate with each other through electrochemical signal codes by releasing neurotransmitters. The dynamic interaction of all these components of different nature results in the emerging property of thought. As such, it is not the result of the sum of all the elements of the brain nor it can be found in each one separately (isolated from the collective behaviour and interaction of the parts). Furthermore, the system adapts to other elements of the body of a person and the external environmental contingencies.

Arriving at this point, it seems appropriate to present the model to this proposal by integrating the general idea of what a complex adaptive system is with the different key points obtained from work within the onomastic sciences?:

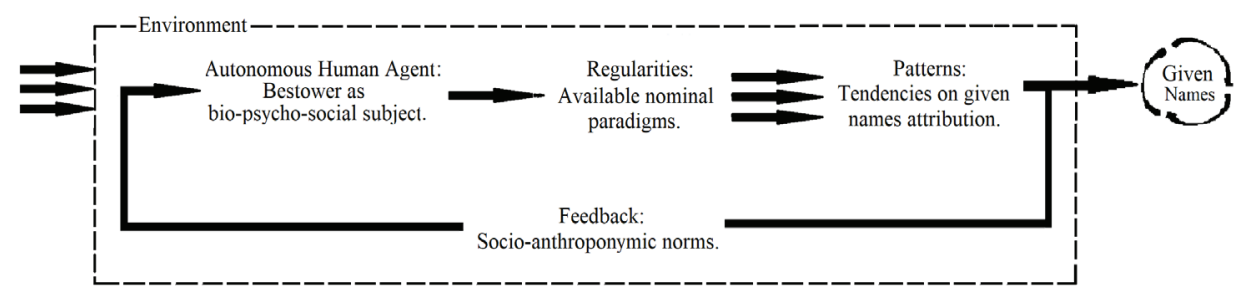

Figure 1. Name-giving process and practices as a complex adaptive system with the category of first names as its emergent property.

Figure 1 shows the name-giving process suggested by Aldrin (2011) as well as the general idea of naming practices (without anchoring the proposal to any in particular) as a complex adaptive system ${ }^{10}$. The category of given names is considered to be emerging from the interaction between the different components

${ }^{9}$ The model presented here is not the final version but part of a $\mathrm{PhD}$ research in progress.

${ }^{10}$ A very first version of the model was orally presented as part of the "Segundas Jornadas Antroponomásticas" held in Mexico and Brazil simultaneously in October 14-16, 2019 and included in the article La construcción de la identidad de género a partir de la selección del nombre de pila (Building Gender Identity from the Selection of the First Name), published in Onomástica desde América Latina, 2020, vol. 1, No 1, pp. 172-198. 
involved in such a system. As part of the visual representation to the model being suggested, the system itself is presented using arrows showing a circular flow, the emergent property is conveyed by another arrow pointing outside to the resulting category, the environment is depicted as a dotted line and the information coming from said environment, by arrows pointing at the system.

The starting point to read this system representation is that of the autonomous human agent. As part of the whole, it takes the role of the bestower in the process and the practices of name-giving. In that regard, it is to be understood not only as an individual but mostly as a member of different dynamic groups (linguistic, cultural and societal). Furthermore, it is not a passive repository of culture and language but an active subject with the potential to change them collectively through social interaction. Accordingly, bestowers are not only users of a language but ongoing members of society and culture, and as such they are to be taken as bio-psychosocial entities. ${ }^{11}$

Human agents interact with one another, and it is within such interaction that they undergo the process of name-giving. As active and ongoing members of different groups, they give names to other human beings. Such human beings are not just about any other mammal of the species but socio-cultural subjects being integrated to the societal, cultural and linguistic community. Therefore, not only do given names function to individualise their bearers but to incorporate them to the group as well. Therefore, socio-cultural subjects would be creating and incorporating other socio-cultural subjects of the community by attributing them a first name.

Interactional networks, therefore, become of utmost importance since it is through these that the membership is built and that the symbolic constructs are not only being shared and transmitted to other generations but also created. Moreover, it is through the name-giving process within social interaction that not only do bestowers negotiate their ongoing membership to the community but the bearers' as well (it could be of a newborn baby or an already member of a certain group within the community ${ }^{12}$ ). Such negotiation is, for the most part, linked to both social and cultural norms being learned as part of different groups within the community. Furthermore, it is related to the construct of self and otherness relevant to the process of identity.

Given name selection as part of the naming process follows societal and cultural guidelines that are being learned, created and recreated through usage. Even more, names actually being chosen begin to develop the stock of first names available for the other members of the community within a certain period of time. In other words,

${ }^{11}$ According to Marta Lamas Encabo (2016, pp. 339-342), human beings are, as interactional subjects, bio-psycho-social entities because they have the capacity to symbolise. She understands symbolisation as an action implying not only the cognitive construction of sense but a subjectively "psychical activity of emotional elaboration."

${ }^{12}$ For example, when an adult changes its social status. 
by choosing a name to integrate another member into the community, the result from the collective agency of the name-giving process generates regularities that result in the nominal paradigm for that community in time.

Such paradigm is being conformed through usage by items already available as well as potentially new ones (which could be completely new words following the structure of the language being expressed in, or words coming from other grammatical categories). Thus, given names enter to the dynamics of socioanthroponymic practices and usage through the process of name-giving that bestowers undergo. On this regard, contrary to Hoffmann and Tóth's proposal (2015), the stock is not already given but being constructed as bestowers interacting with other members of the community undergo the process of name-giving.

Regularities in the paradigm will come from languages being used by interacting subjects who are also members of society and culture and as such they will give rise to tendencies through time. Such tendencies will be the basis for emerging patterns that later on will develop into socio-anthroponymical norms. Such norms are to be regarded as feedback coming from the system itself that will regulate future choices of ongoing members of the community. Such norms are not only of the linguistic but the societal and cultural nature as well, and they will serve as guidelines to bestowers as part of the community by forming them within the customs and habits of the group.

Taking all this into consideration, given names as a category would be the result of the dynamic interaction of all the above and not a preconceived one from the abstract system of language. The complex adaptive system would include interaction of human beings as bio-psycho-social entities as members to culture and society. Such autonomous human agent will choose names to integrate other human beings into the socio-cultural network to which they are part of, and where they have been formed into.

By undergoing the name-giving process, bestowers will be "activating" items into the flow of the system and creating an available paradigm. The paradigm will evolve into patterns as part of naming practices, and will result in regulating feedback to other members of the community. Furthermore, both the name-giving process and the naming practices will adapt to changes of a bigger macro flow of society, language and culture as part of the environment. For example, for important historical events such as a change of regime, or to cultural alterations such as gender equality.

The category of first names is, then, an emergent property from the interaction between the following components of the system: The sociocultural subjects (as members to different dynamic groups within the community) that undertake the role of the bestower, the available paradigm of names formed by the choices made through the name-giving process integrated to the naming practices for each community in time, the patterns resulting from the continuous flow of such paradigm, 
and the socio-anthroponymic norms that regulate bestower's preferences according to the system itself. For that reason, it cannot be regarded as having only a linguistic facet, independent and isolated form the cultural and societal ones.

Perhaps an example would help to better explain the complex system being proposed in this work: let us consider the case of the Basque in Mexico, more specifically in Mexico City. ${ }^{13}$ Because of space issues, it is not possible to present with an in-depth analysis and explanation but hopefully it will contribute to the general idea being presented in the paper.

The Basque community has a long history of external migration flows to Mexico. From economical migration to political exile, there have been different reasons for the Basque to enter to the country. Sometimes, Basque immigrants remain in Mexico and make a home in this new place that has welcomed them. In these cases, they tend to integrate to the reception country in different degrees, many times according to the type of mobility they were part of in the first place. However, such adaptation to their new surrounding does not imply the loss of their previous cultural, linguistic and social heritage but the combination of both. And this is something that can be witnessed when choosing names for their children in the country of reception.

The entry to the system is given by the information coming from the environment. In the case of the Basque, the general surrounding can be found in different historical events that gave the sufficient conditions for people to move out of their own country. Hence, there could be, for example, the Spanish Civil War by which over 20 thousand people were exiled for political reasons or the lack of job opportunities that come with past economic crises. All of these socio-historical factors would be translated as information that the system, as an open and adaptive one, acquires. In this case, some of the information being integrated to the namegiving process and practices could be that of the place of origin, the place of reception and the type of mobility.

Basque immigrants that arrived and stayed in the country started creating and integrating into different social networks, at the beginning solely to the already existent supporting groups of previously arrived immigrants from their country. As they continued in Mexico, such networks might have been diversified, including not only people close to their own background but Mexicans as well. Then the interactions that the Basque created were, for once, amongst other immigrants, and for other, with people born and raised in Mexico. And, depending on the type and time of mobility, they would also keep an active communication with their previous social networks back at home.

${ }^{13}$ The example given at this point was obtained by performing fieldwork within the Basque community in Mexico City as part of a PhD dissertation. Interviews with the descendants of different Basque migrations as well as ethnographic observation were performed. 
Interaction between the Basque and all of this diversity, given by the already existent population in Mexico and their own social networks, influenced the choice of names given to their offspring born in the recipient country. Therefore, they were faced with the option of taking from the already existent repertory in Spanish that the recipient country was on the process of organising, or choosing a first name from their Basque heritage. In many cases, they inclined for the latter but without forgetting the place they were now living in. Hence, they preferred names that belong to the Euskara repertory but that were easy for Spanish speaking Mexicans to pronounce and remember. For example, they would choose names such as Iker and not Aitor for men, or Lorea and not Gurutzne for women.

These regularities in the conformation of the nominal paradigm by the choices taken as part of their social interaction then became a tendency within the community itself and, sometimes, even integrated to the general Mexican repertory (for example, Iker became a name in fashion in Mexico at some point). Tendencies coming from the ongoing organisation of the stock returned to the autonomous human agents as feedback in form of a norm by which new bestowers, as part of the community of descendants from a Basque migration flow, would prefer and choose names expressed in Euskara that were accessible for Spanish speakers.

The category as an emergent property of the system in this very specific example would be created by the interaction of all of the above, having the system becoming stable through time by learning from the information given by the environment. On this regard, the prototype theory as taken from cognitive linguistics and applied to first names by Yolanda G. López Franco (2020) becomes of great relevance as well as Willy Van Langendonck's (2007) proposal about the distinction between proper names as lemma and function. But that is a topic for yet another paper. For the time being, the purpose of this article was to present a model to explore the possibility of given names as an emergent property of a complex adaptive system found in the name-giving process and practices.

\section{Final words}

Given names are part of languages and cultures emerging from social interaction. For that reason, they can be regarded as linguistic, cultural and societal phenomena all together. The category results an emergent property of the dynamic interaction between language in use, shared symbolic frames and social interactions recognised in the name-giving process and naming practices. For that reason, it needs to be regarded as a whole and not as the sum of separated, individual parts.

The idea of a complex adaptive system in which a multiplicity of heterogeneous variables interacts with each other and their environment seems to significantly contribute to the study of given names. However, more work needs to be done in this regard to truly recognise its worth in the area. The model presented here is only a starting point to the, hopefully, future application of the notion not only from 
a theoretical but also an empirical point of view. On that same note, many questions arise and are left unanswered in this study. For instance, whether the proposal could also be applied to other types of anthroponyms or to other proper name categories (such as toponyms or brand-names), and to what extent.

\section{References}

AINALA, Terhi - ÖSTMAN, Jan-Ola: Socio-Onomastics. The Pragmatics of Names. Amsterdam: John Benjamins Publishing Company 2017. 231 p.

ALDRIN, Emilia: Choosing a Name $=$ Choosing Identity? Towards a Theoretical Framework. In: Actes del XXIV Congrés Internacional d'ICOS sobre Ciències Onomàstiques, 2011, pp. 392-401 (Annex. Secció 4: Els noms en la vida quotidiana).

BERTALANFFY, Ludwig Von: Teoría general de los sistemas. México: Fondo de Cultura Económica 1976. 311 p.

BRAMWELL, Ellen S.: Naming in society: a cross-cultural study of five communities in Scotland. Glasgow: University of Glasgow 2012. 434 p. (PhD thesis)

BUCHOLTZ, Mary - HALL, Kira: Identity and interaction: a sociocultural linguistic approach. In: Discourse Studies: An Interdisciplinary Journal for the Study of Text and Talk, 2005, Vol. 7, No 4-5, pp. 586-614.

CAPRINI, Rita: Nomi propri. Pisa: Edizioni dell'Orso 2001. 160 p.

CASTRO ALFÍN, Demetrio: Antroponimia y sociedad. Una aproximación sociohistórica al nombre de persona como fenómeno cultural. Navarra: Universidad Pública de Navarra 2014. 172 p.

DÍAZ MATA, Alfredo: Tres aproximaciones a la complejidad. In: Contaduría y Administración, 2012, Vol. 57, No 1, pp. 241-264.

FERNÁNDEZ JUNCAL, Carmen: El sistema antroponímico como diasistema. In: Nouvelle Revue d'Onomastique, 2011, vol. 53, pp. 141-150.

FERNÁNDEZ JUNCAL, Carmen: Evolución de los usos antroponímicos en España. In: Moenia, 2020, Vol. 25, pp. 149-177.

FINE, Agnès: Transmission des prénoms et parenté en Pays de Sault, 1740-1940. In: Le prénom. Mode et histoire. Paris: Entretiens de Malher EHESS 1984, pp. 109-125.

GARCÍA GALLARÍN, Consuelo - BRAVO LLATAS, María del Carmen: La innovación antroponímica durante la Segunda República. In: Onomástica, deonomástica y documentación. Kassel: Reichenberger, 2019, pp. 27-55.

GARCÍA, Rolando: Sistemas complejos. Conceptos, método y fundamentación epistemológica de la investigación interdisciplinaria. Barcelona: Gedisa 2006. 202 p.

GARCÍA, Rolando: Interdisciplinariedad y sistemas complejos. In: Ciencias sociales y formación ambiental. Barcelona: Gedisa 1994, pp. 85-124.

GELL-MANN, Murray: Simplicity and Complexity in the Description of Nature. In: Engineering and Science 1988, pp. 2-9.

HAIDAR, Julieta: Debate CEU-Rectoría. Torbellino pasional de los argumentos. México: Universidad Nacional Autónoma de México 2006. 514 p. 
HOFFMANN, István - TÓTH, Valéria: Viewpoints on the cognitive-pragmatic description of personal names. In: Word, 2015, Vol. 61, No 2, pp. 141-164.

JIMÉNEZ SEGURA, Selene: La construcción de la identidad de género a partir de la selección del nombre de pila. In: Onomástica desde América Latina, 2020, Vol. 1, No 1, pp. 172-198.

KRETZSCHMAR, William A. Jr: Language and Complex Systems. Cambridge: Cambridge University Press 2015. 230 p.

LADYMAN, James - LAMBERT, James - WIESNER, Karoline: What is a complex system? In: European Journal for Philosophy Science, 2013, Vol. 3, No 1, pp. 33-67.

LAMAS ENCABO, Marta: Usos, dificultades y posibilidades de la categoría género. In: El género. La construcción cultural de la diferencia sexual. México: Universidad Nacional Autónoma de México, Centro de Investigaciones y Estudios de Género 2015, pp. 331-366.

LÓPEZ AGUILAR, Fernando: The Altepetl: Fractal modeling of a Pre-Hispanic Human Agency. In: Fractal Analysis, Applications in Health Sciences and Social Sciences. InTech Publisher 2017, pp. 131-140.

LÓPEZ FRANCO, Yolanda Guillermina: Las relaciones intercategoriales e intracategoriales en antroponimia. El caso de los nombres de pila en francés de Francia y en español de México. In: Onomástica desde América Latina, 2020, Vol. 1, No 1, pp. 222-247.

MAÍZ ARÉVALO, Carmen: Nombre propio e identidad cultural. Madrid: Sílex Universidad 2010. 180 p.

MORENO ALMÁRCEGUI, Antonio - ZABALZA SEGUÍN, Ana: El origen histórico de un sistema de heredero único: el Prepirineo Navarro, 1540-1739. Madrid: Ediciones Rialp 1999. $431 \mathrm{p}$.

MORIN, Edgar: Introducción al pensamiento complejo. Barcelona: Gedisa 2009. 167 p.

MORIN, Edgar: El paradigma perdido. Ensayo de bioantropología. Barcelona: Editorial Kairós 2005. 263 p.

MOSKO, Mark S. - DAMON, Fred: On the Order of Chaos: Social Anthropology and the Science of Chaos. Oxford: Berghahn Books 2005. 296 p.

OFFROY, Jean-Gabriel: On nomme un enfant. Choix du prénom et projet parental. Lille: Atelier National de Reproduction des Thèses 1992.

SANGOÏ, Jean-Claude: La transmission d'un bien symbolique: le prénom. In: Terrain 4. Carnets du Patrimoine Ethnologique, 1985, pp. 70-76.

VAN LANGENDONCK, Willy: Theory and Typology of Proper Names. New York: Mouton de Gruyter 2007. 378 p. 